\title{
O uso da água na produção sojeira em fazenda do município de Santarém, Amazônia, Brasil
}

Como um indicador relacionado ao uso da água, tem-se a pegada hídrica $(\mathrm{PH})$, que vem sendo muito discutida por ressaltar a grande importância de se ter uma adequada gestão de uso de água. A PH dispõe a caracterização de três tipos de água básica, que são as águas azul, verde e cinza. O trabalho visa estimar a quantidade de água utilizada na cadeia produtiva da soja em uma fazenda situada no município de Santarém, região oeste do Pará (AM), além de almejar produzir insumos científicos que proporcionem a comparação dos dados obtidos através deste estudo na Amazônia com as informações e médias dispostas da cultura da soja no Brasil. A metodologia utilizada foi a da Water Footprint Network, baseada nos preceitos da pegada hídrica fundamentada por Chapagain et al. (2003). Os resultados obtidos na área de estudo foram 779,30m3.ton-1de PH verde, 0,125m3.ton-1 de PH azul e 166,67m3.ton-1 de $\mathrm{PH}$ cinza, sendo $946,09 \mathrm{~m}^{3}$.ton-10 valor da pegada hídrica total. Comparando com as literaturas nacionais condizentes, fica notório que o valor de PH obtido nesta pesquisa é consideravelmente menor que nas demais regiões do país, sendo possível interpretar através de análises que, do ponto de vista hídrico, é mais viável se produzir soja na Amazônia do que em outro lugar do Brasil. Um fator de suma importância para esse resultado faz referência ao regime de precipitações constantes que há em determinada época do ano (período de safra) na região amazônica; isso diminui muito ou reduz a nada a utilização de irrigação na produção da soja neste bioma. Devido ao fator citado não ser característica das demais regiões brasileiras, estas precisam irrigar muito mais suas culturas (PH azul), o que eleva grandemente o valor da PH total. Deste modo, conclui-se a necessidade de ser aplicada uma melhor gestão no uso da água em produções do Brasil visando impactos ambientais cada vez menores No mais, espera-se que esta pesquisa sirva como insumo para estas ações de gestão melhorada de recursos hídricos em produções de soja e demais culturas que fazem uso da irrigação.

Palavras-chave: Pegada Hídrica; Amazônia; Produção de soja; Gestão de recursos hídricos.

\section{The use of water in soybean production in a farm in the municipality of Santarém (AM)}

\begin{abstract}
As an indicator related to water use, there is the water footprint (PH), which has been much discussed because it underscores the great importance of havin proper management of water use. PH has the characterization of three types of basic water, which are blue, green and gray. The work aims to estimate the amount of water used in the soybean production chain in a farm located in the municipality of Santarém, western Pará (AM), and aims to produce scientific inputs that provide a comparison of data obtained through this study in the Amazon with information and averages disposed of soybean crop in Brazil. The methodology used was Water Footprint Network, based on water footprint precepts based on Chapagain et al. (2003). The results obtained in the study area were $779.30 \mathrm{~m} 3$. ton-1 of green PH, 0.125m3.ton-1 of blue PH and $166.67 \mathrm{~m} 3$.ton-1 of gray PH, with $946.09 \mathrm{~m}^{3}$.ton-1 as the footprint value. total hydro. Comparing with the appropriate national literature, it is noticeable that the $\mathrm{PH}$ value obtained in this research is considerably lower than in other regions of the country, being possible to interpret through analyzes that, from the water point of view, it is more viable to produce soybeans in the Amazon than elsewhere in Brazil. A very important factor for this result refers to the constant precipitation regime that exists at a certain time of the year (crop season) in the Amazon region; This greatly reduces or reduces the use of irrigation in soy production in this biome. Because the aforementioned factor is not characteristic of other Brazilian regions, they need to irrigate their crops much more (blue PH), which greatly increases the value of total PH. This concludes the need for better management of water use in Brazilian productions aiming at decreasing environmental impacts. Moreover, it is hoped that this research will serve as input for these actions of improved management of water resources in soybean and other crops that make use of irrigation.
\end{abstract}

Keywords: Water footprint; Amazon; Soybean production; Water resource management.

Topic: Uso de Recursos Naturais

Reviewed anonymously in the process of blind peer.
Received: 22/08/2018

Approved: 27/08/2018
Ilze Caroline Gois Braga Pedroso

Universidade Federal do Oeste do Pará, Brasil

http://lattes.cnpq.br/8375527746629274

gbpcaroline@gmail.com

Urandi João Rodrigues Junior

Universidade Federal do Oeste do Pará, Brasil

http://lattes.cnpq.br/1439410429991806

urandijunior@hotmail.com
Referencing this:

PEDROSO, I. C. G. B.; RODRIGUES JUNIOR, U. J.. O uso da água na produção sojeira em fazenda do município de Santarém, Amazônia, Brasil. Revista Ibero-Americana de Ciências Ambientais, v.9, n.6, p.283-294, 2018. DOI: http://doi.org/10.6008/CBPC21796858.2018.006.0027 


\section{INTRODUÇÃO}

A Amazônia possui uma considerável área geográfica, que se estende por vários países; no entanto, sua maior parte está situada em território brasileiro. Nela, encontra-se a maior bacia hidrográfica do planeta, que é a amazônica, cuja ocupação engloba vários estados do país, dentre eles, o Pará. Apesar do volume imenso que tal bacia possui, o uso de água para a produção de alimentos tem causado preocupação; isto devido a cada vez maior utilização dos recursos hídricos na produção de culturas como a da soja que, nos últimos anos, muito tem crescido no estado do Pará. É notório que a inserção de conceitos ambientais como o de sustentabilidade e de utilização de recursos hídricos - é de enorme importância, pois a água e sua gestão melhorada se constituem em elementos imprescindíveis à garantia da capacidade de produção.

Como um indicador relacionado ao uso da água, tem-se a pegada hídrica (PH). Ela tem sido muito discutida pelos cientistas para ressaltar a grande importância de se ter uma adequada gestão de uso de água (SILVA et al., 2013). Gerbens-Leenes et al. (2012) define a PH como uma medida volumétrica que mostra o consumo de água doce (em metros cúbicos por ano) alocadas no tempo e no espaço, isto é, tem a principal finalidade de quantificar o uso da água no decorrer da produção (YU, 2010).

A pegada hídrica dispõe a caracterização de três tipos de água básica que são a água azul, verde e cinza. A PH azul está relacionada com a água consumida em uma bacia hidrográfica, seja ela subterrânea ou superficial, enquanto a pegada verde corresponde à água que precipita, mas não escoa superficialmente e nem fica armazenada em bacias subterrâneas, porém, permanece temporariamente no solo ou na vegetação; é a água consumida da chuva pela produção. Já a PH cinza indica o quanto a água está poluída, pois se refere à quantidade de água necessária para diluir, sanar ou tratar efluentes de forma que, ao final do processo, a qualidade da água esteja dentro dos padrões aceitáveis (HOEKSTRA et al., 2011).

O cálculo da pegada hídrica se mostra, então, como uma ferramenta que auxilia na manutenção sustentável de água, possibilitando o crescimento de políticas públicas para melhorar a gestão de água pela comunidade. (MENDONÇA et al., 2013). Chapagain et al. (2003) desenvolveu fórmulas que calculam a PH de acordo com seu tipo, seja ela azul, verde ou cinza e, apesar da fórmula pronta para se fazer o cálculo, podese aplicar adaptações para o tipo de pesquisa necessária (PALHARES, 2014).

A cadeia produtiva brasileira é complexa e a produção dos bens alimentícios exportados é alta. 0 Brasil é um bom exemplar quando está em pauta a produção primária, como o caso do açúcar e da soja. Por este motivo a água como produto de exportação indireta brasileira, remete a um risco ambiental em escala global, pois, fica evidente quem supre a questão da escassez hídrica de outras regiões do mundo. Todos os produtos exportados, principalmente os agrícolas, como a soja, demandam um grande volume de água (CARMO et al., 2007).

A partir disso, é de grande importância frisar a inserção do termo água virtual (AV) na pegada hídrica. Este faz referência à questão de a maioria da água utilizada para produzir determinado produto não estar contida nele (SILVA et al., 2013). A mensuração do volume de água doce envolvida ao longo das várias fases do processo produtivo de qualquer produto (mercadoria, bem ou serviço) industrial ou agrícola passa a ser denominado de água virtual (HOEKSTRA et al., 2007). 
Autores como Aldaya et al. (2010) também argumentam que a AV pode ser compreendida como uma fonte alternativa de água, pois regiões e países com baixa disponibilidade hídrica têm utilizado desse recurso para garantir o abastecimento de produtos agrícolas para seus habitantes. O Brasil é um grande produtor mundial de alimentos e, consequentemente, um dos maiores exportadores de água virtual por meio de suas commodities (CARMO et al., 2007).

As três principais vertentes de uso consuntivo de água no Brasil são abastecimento doméstico, produção industrial e produção agrícola. Em vários países estas três finalidades chegam a corresponder cerca de mais de dois mil litros de água por habitante por dia (CHRISTOFIDIS, 2013). No que faz referência aos âmbitos que abrangem a agricultura, a pegada hídrica tem demonstrado ser um importante fomentador de dados e, consequentemente, de informações e tomadas de decisão relacionadas à economia e à sustentabilidade.

Pimentel (2004) afirma que a quantidade de água usada para alguns produtos é muito elevada, e propõe que esse gasto pode ser diminuído a partir da mudança da dieta alimentar de várias populações. Desta forma, o ideal seria a readaptação alimentar com a substituição de alimentos cuja cadeia produtiva exija demanda maior de água.

A partir destas considerações, o presente trabalho objetiva estimar a quantidade de água utilizada na cadeia produtiva da soja em uma fazenda situada no município de Santarém, região oeste do Pará, Amazônia, Brasil, utilizando a ferramenta da pegada hídrica. Além disso, almeja-se produzir insumos científicos que proporcionem a comparação dos dados obtidos através deste estudo em Santarém, na Amazônia, com as informações e médias dispostas da cultura da soja no Brasil.

\section{METODOLOGIA}

Foi definida uma área de pesquisa de campo exploratória dentro da região amazônica, isto considerando critérios ligados à disponibilidade de acesso físico, de acesso às informações e a importância dessa região no quesito ambiental, com relação à obtenção de dados e informações como insumos para comparações a nível nacional.

Observando a importância de obter estudos que viabilizem maiores informações do bioma Amazônia, principalmente no que tange aos recursos hídricos, estimou-se a pegada hídrica total da produção da cultura de soja de uma fazenda no estado do Pará, situada na PA-370, Santarém - Curuá Una na comunidade de Boa Esperança, nas coordenadas (Sistema UTM Geográfico) 243’24:78S Latitude $/ 54^{\circ} 29^{\prime} 00: 330$ Longitude, e que possui uma área total de plantio de aproximadamente 400 hectares. No mais, a fazenda está localizada na região hidrográfica do Rio Tapajós que trabalha com o cultivo da soja desde 2000.

Trata-se de uma área de médio porte para a realidade local e é uma das pioneiras em plantio de soja na região, segundo seu proprietário. Houve duas idas à fazenda de estudo, a primeira denominada entrevista e visita (etapa exploratória) e a segunda, onde foram consolidadas as etapas de coleta de dados geográficos e de uso da água. 
Para a análise da cadeia produtiva da soja, foi utilizada, especificamente, uma metodologia baseada nos preceitos da pegada hídrica fundamentada por Chapagain et al. (2003), indicador mundialmente reconhecido para a mensuração de impactos e quantificação do uso dos recursos hídricos em processos produtivos e atividades antrópicas. A estratégia de adaptação da pegada hídrica para diferentes contextos produtivos é prevista no Manual da Avaliação da Pegada Hídrica - Estabelecendo o padrão global, publicado em 2011 pela Water Footprint Network, instituição global que desenvolveu a metodologia e a dissemina cientificamente.

Para a análise, definiu-se, primeiramente, o escopo e os objetivos do estudo na cadeia produtiva, seguindo as indicações da metodologia da pegada hídrica. Chapagain et al. (2003) salienta que as cadeias produtivas possuem ramificações e, em muitos casos, processos circulares que podem gerar duplicação na contabilização e mensuração do uso dos recursos hídricos. A figura 1 apresenta a definição do escopo do trabalho e suas etapas.

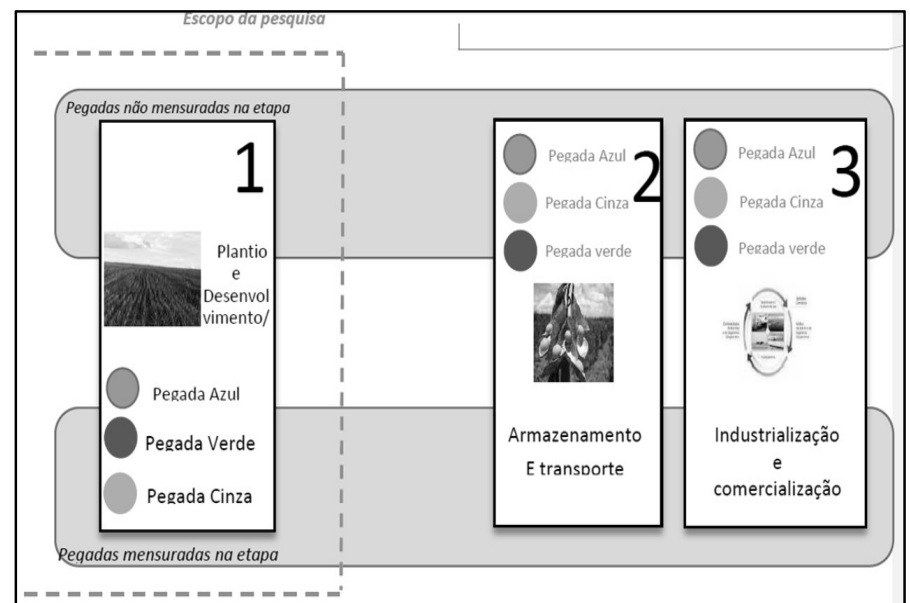

Figura 1: Cadeia produtiva da soja, escopo da pesquisa e pegada hídrica considerada em cada etapa. Fonte: Rodrigues Junior et al. (2015).

Delimitou-se o escopo do presente trabalho ao plantio e ao desenvolvimento do grão, etapas exclusivamente operacionalizadas dentro das fazendas. Essas etapas correspondem à pegada hídrica da soja para sua produção in natura, seguindo a metodologia adotada em grande parte dos trabalhos com pegada hídrica, entre eles Hoekstra et al. (2007), criador da metodologia, que definiu médias mundiais para grãos e produtos industrializados. As etapas 2 e 3 apontadas na figura 1 são referentes ao restante da cadeia produtiva da soja: armazenagem e transporte e industrialização e comercialização.

A definição do escopo do trabalho se deu, principalmente, pela maior facilidade de acesso aos dados na fazenda (área de estudo), enquanto nas etapas 2 e 3 a diversidade de cenários é muito grande. Isso fica claro quando se considera, por exemplo, que algumas fazendas possuem seu próprio sistema de armazenamento, enquanto outras fazendas fazem a venda direta da soja e não armazenam o grão após colhido.

Outras ainda adotam sistemas de armazenagem para atender demandas específicas, ou seja, existe uma variedade de possibilidades dependendo de cada produtor e fazenda. O tipo de armazenamento também gera variação no tipo de transporte, aumentando assim as possibilidades de aumento de escopo e 
a falta de acesso aos dados e informações. Situação que se repete na etapa 3 da cadeia produtiva da soja, pois a variedade de produtos industrializáveis da soja é grande.

\section{Análise Quantitativa: Cálculo da Pegada Hídrica}

Para o cálculo da quantidade de água utilizada na cadeia produtiva da soja na fazenda em questão foi adotada a metodologia da pegada hídrica total. Além dos dados da pesquisa de campo (produtor), foram utilizados dados secundários oriundos de literatura científica e relatórios técnicos de órgãos especializados (EMBRAPA, 2000).

O cálculo da pegada hídrica segue a metodologia apresentada por Hoekstra et al. (2011), sintetizada na equação PHtotal $=$ PHverde + PHazul + PHcinza, onde: PHtotal: Pegada Hídrica total do processo de crescimento de cultura $\left(\mathrm{m}^{3} \cdot \mathrm{t}^{-1}\right)$; PHverde: Pegada Hídrica Verde $\left(\mathrm{m}^{3} \cdot \mathrm{t}^{-1}\right)$; PHazul: Pegada Hídrica Azul $\left(\mathrm{m}^{3} \cdot \mathrm{t}^{-1}\right)$; e PHcinza: Pegada Hídrica Cinza $\left(\mathrm{m}^{3} \cdot \mathrm{t}^{-1}\right)$. Para mensurar o uso dos recursos hídricos na cadeia produtiva, do ponto de vista quantitativo, utilizaram-se dados do período de safra da soja e informações obtidas junto aos produtores rurais pesquisados.

Inicialmente, foi contabilizada a pegada verde da cultura - a água de precipitação que evapotranspira na cultura do grão - com o auxílio do programa computacional CROPWAT (FAO, 2010), que indica a quantidade de água necessária para o desenvolvimento da planta, apresentando recomendações para práticas de irrigação de acordo com o suprimento de água da região ao longo do ano, levando em consideração as chuvas durante o período. Além disso, foi utilizado também o programa computacional CLIMWAT $(F A O, 2010)$, que fornece dados médios de precipitação com base em 30 anos de informações de dados agroclimáticos para um local por meio da interpolação de dados disponíveis de estações de monitoramento na região.

Tabela 1: Pegada verde da soja: dados para cálculo, suas respectivas fontes e unidades.

\begin{tabular}{|l|l|c|}
\hline \multicolumn{1}{|c|}{ Dados } & \multicolumn{1}{|c|}{ Fonte dos dados } & Unidade \\
\hline Sacas de soja produzidas (MÉDIA DA ÁREA) & Pesquisa com o produtor da área escolhida & Sacas \\
\hline Dimensão da área & $\begin{array}{l}\text { Pesquisa com o produtor da área escolhida, } \\
\text { documentação da área }\end{array}$ & Há \\
\hline $\begin{array}{l}\text { Produção Efetiva em kg (SACAS X HECTARES X KG } \\
\text { POR SACA) }\end{array}$ & Pesquisa com o produtor da área escolhida & $\mathrm{Kg}$ \\
\hline Quantidade de soja por saca & EMBRAPA - padrão nacional & $\mathrm{Kg}$ \\
\hline Média diária de evapotranspiração da cultura & $\begin{array}{l}\text { Software CROPWAT (FAO) e dados do software CLIMWAT } \\
\text { (FAO) }\end{array}$ & $\mathrm{mm}^{-1}$ \\
\hline Período da safra (SAFRA) & Pesquisa com o produtor da área de pesquisa & Dias $^{\text {tha }}$ \\
\hline Produtividade & Resultado obtido com os dados acima & t.ha $^{-1}$ \\
\hline
\end{tabular}

Fonte: Rodrigues Junior et al. (2015).

$\mathrm{Na}$ tabela 1, os dados obtidos em pesquisa com os produtores rurais foram produto das entrevistas realizadas em propriedades da região da fazenda que é área de estudo. Os dados 'Sacas de soja produzidas', 'tamanho da área em hectares' e período da safra e dias da safra' foram também obtidos exclusivamente desta maneira, pois, cada área possui suas especificidades. 'A quantidade de soja por saca' foi obtida através do relatório técnico da EMBRAPA, tratando-se de um padrão nacional. Os dados referentes à evapotranspiração diária de água verde são oriundos do software CROPWAT, utilizado para estimar a 
evapotranspiração de culturas agrícolas com o intuito de desenvolver planejamentos mais efetivos para o uso da água na produção agrícola (FAO, 2010).

O CROPWAT usa dados agrometeorológicos, dados do solo e dados da cultura. O uso do software está relacionado ao uso de outro software apresentado pela FAO, o CLIMWAT 2.0 que fornece uma base de dados de 30 anos de informações. Os resultados obtidos no software CROPWAT são referentes aos períodos de safra e safrinha das áreas de estudo, e são feitos separadamente para cada área e etapa da cadeia produtiva.

Os dados da tabela 1 foram utilizados para determinar a produtividade da área. Após a pesquisa de campo na área de estudo e a obtenção dos dados, tornou-se possível empregar a equação 1 (RODRIGUES JUNIOR et al., 2015) para o cálculo da pegada verde na cultura. Por fim, chegou-se ao resultado da quantidade de água verde utilizada na cultura da soja na região de estudo, apresentada em $\mathrm{m}^{3}$ ton $^{-1}$. No presente trabalho, optou-se pela utilização do padrão adotado por Chapagain et al. (2004) no que tange à incorporação de água verde no produto, que pode ser apresentada como a fração de água que compõe o cultivo após a colheita.

Porém, a maioria dos estudos não contabiliza esse valor, pois ele representa de 0,1 a $1 \%$ do total da pegada hídrica verde, segundo Hoekstra $(2009,2011)$. Tem-se Consumo de água verde $=$ Fator de conversão x Evapotranspiração da cultura em $\mathrm{mm}$, onde Consumo de água verde: $\left(\mathrm{m}^{3} \cdot\right.$ ha $\left.{ }^{-1}\right)$; Fator de conversão: $(10=$ $10000 \mathrm{~m}^{2}$.ha-1 $\times 10^{-3} \mathrm{~m} \cdot \mathrm{mm}^{-3}$ ); e Evapotranspiração da cultura em mm: (primeiro dia de plantio até a colheita).

A pegada hídrica azul é medida com base na quantidade de água utilizada para serviços, proveniente de fontes subterrâneas ou superficiais tendo em vista se a fazenda de estudo utiliza ou não irrigação para o cultivo da soja, conforme dados obtidos junto ao produtor. Logo, dependendo da situação, a pegada azul para essa atividade pode ser considerada igual a zero, em consonância com Rodrigues Junior et al. (2015), Palhares (2011) e Hoekstra et al. (2011). Porém, também poderá ser considerada a pegada azul da cultura na contabilização da água utilizada para serviços dentro da propriedade rural pesquisada.

Como serviços se entende que podem ser incorporados à PH azul, a água utilizada para lavagem de maquinários para plantio, a água utilizada para diluição dos insumos para plantio (herbicidas, inseticidas), para dessecação que é uma prática utilizada na área de produção de grãos, com o objetivo de controlar as plantas daninhas ou uniformizar as plantas com problemas de haste verde/retenção foliar (EMBRAPA, 2000), além de serviços gerais diretamente ligados à produção da cultura. A parcela de água utilizada é considerada pegada azul desde que sua fonte de extração seja de águas superficiais ou subterrâneas (HOESKTRA, 2011). Para a metodologia adotou-se o volume de $75 \mathrm{~L}_{\text {. ha }}{ }^{-1}$ para a diluição dos insumos, dado obtido juntamente aos produtores rurais entrevistados, considerando cinco aplicações por safra em média.

A pegada cinza representa a quantidade de recurso hídrico necessário para diluir os poluentes lançados na natureza. Usualmente, esses são compostos por fertilizantes (nitrogênio, fósforo, dentre outros), pesticidas e inseticidas, e a metodologia aponta que se deve mensurar apenas o fluxo de resíduos para corpos hídricos, que se trata apenas de uma parcela do total de aplicação de fertilizantes e inseticidas na cultura (HOEKSTRA et al., 2011). Além disso, a cultura da soja é por si grande produtora e recicladora de Nitrogênio (N) e exportadora de Cálcio (Ca) e Potássio (K). 
O nitrogênio representa $69,88 \%$ da quantidade de extração da cultura e 59,24\% da exportação da cultura. A extração representa a quantidade de nutrientes contidos na parte aérea (incluindo os grãos) da cultura, já a exportação, a quantidade de nutrientes contida somente nos grãos (MALAVOLTA, 1989). No presente trabalho, a atenção foi direcionada ao Nitrogênio (RODRIGUES JUNIOR et al., 2015), seguindo também a recomendação de Hoekstra et al. (2009) que aponta o elemento como o poluente mais crítico para esta cultura, critério seguido em grande parte das produções nessa área como Ercin et al. (2011) e Arena et al. (2011).

O cálculo da pegada hídrica cinza utilizado na cultura de soja da área de estudo é demonstrado na equação 2 (RODRIGUES JUNIOR et al., 2015). Para o parâmetro de lixiviação, foi utilizada a recomendação de 0,10 citada por Hoekstra et al. (2007) para a cultura de soja, enquanto para a taxa de aplicação foram utilizados dados da EMBRAPA (2000) que apontam $50 \mathrm{~kg} / \mathrm{N} \cdot \mathrm{ha}^{-1}$ para essa cultura. Hoesktra (2009) sugere a adoção do valor zero para a concentração natural de nitrogênio no corpo hídrico. Para a concentração máxima de Nitrogênio no corpo hídrico são utilizados os parâmetros da resolução 357 do CONAMA para rios de Classe II.

Os dados para aplicação na equação da PH cinza têm as fontes apontadas na tabela 2. Propõe-se a equação PHcinza = L.Q/(Cmax.Cnat), na qual PHcinza: Pegada Hídrica cinza, em $\mathrm{m}^{3} \cdot \mathrm{ha}^{-1}$; L: Fração de lixiviação; Q: Taxa de aplicação de químicos por hectare $\left(\mathrm{kg} \cdot \mathrm{ha}^{-1}\right)$; $\mathrm{Cmax}$ : Concentração máxima admissível do poluente no meio aquático receptor $\left(\mathrm{kg} / \mathrm{m}^{3}\right)$; e Cnat: Concentração natural do poluente no meio aquático receptor $\left(\mathrm{kg} / \mathrm{m}^{3}\right)$. Ao final do cálculo das pegadas verde, cinza e azul os resultados são apresentados em volume de água utilizada nessa cadeia produtiva. Todas as tabelas e fórmulas apresentadas foram estruturadas e organizadas em uma planilha eletrônica, sistematizando os processos da metodologia criada.

Tabela 2: Pegada cinza da soja: dados para cálculo e suas respectivas fontes.

\begin{tabular}{|l|l|c|}
\hline \multicolumn{1}{|c|}{ Dado } & \multicolumn{1}{|c|}{ Fonte dos dados } & Unidade \\
\hline Fração de Lixiviação (10\%) & CHAPAGAIN (2006) & $\mathrm{kg}^{-1} \mathrm{ha}^{-1}$ \\
\hline $\begin{array}{l}\text { Taxa de Aplicação de produtos químicos por } \\
\text { hectare }\end{array}$ & $\begin{array}{l}\text { Hectares: área de estudo taxa de aplicação: } \\
\text { EMBRAPA (2000) }\end{array}$ & Dado \\
\hline Poluente mais crítico & HOESKTRA (2009) & $\mathrm{kg} / \mathrm{m}^{3}$ \\
\hline $\begin{array}{l}\text { Concentração máxima admissível do poluente no } \\
\text { meio aquático }\end{array}$ & Resolução 357 (CONAMA) & $\mathrm{kg} / \mathrm{m}^{3}$ \\
\hline $\begin{array}{l}\text { Concentração natural do poluente no meio } \\
\text { aquático receptor }\end{array}$ & HOESKTRA (2009) & Dias \\
\hline Período da safra & Pesquisa com o produtor da área escolhida & ton.ha-1 \\
\hline Produtividade & Pesquisa com o produtor da área escolhida & \\
\hline
\end{tabular}

Fonte: Rodrigues Junior et al. (2015).

\section{RESULTADOS}

\section{Resultados Quantitativos: Pegada Hídrica}

A figura 2 mostra as estações meteorológicas próximas à fazenda estudada identificadas pelo programa CLIMWAT (FAO, 2010). Selecionou-se a estação de Santarém, localizada no mesmo município da área de estudo. Os dados obtidos foram utilizados no programa CROPWAT (FAO, 2010), que se baseia na equação de Penman-Monteith para determinação da evapotranspiração de referência (ETO), com base em: 
temperatura máxima e mínima, umidade relativa do ar, velocidade do vento, radiação solar e precipitação total mensal (FAO, 2010).

Foram inseridos no programa computacional os seguintes dados do solo: tipo (classificação), capacidade de água disponível (CAD) e taxa de infiltração máxima; e os dados da cultura: coeficientes de cultivo $(\mathrm{kc})$, duração dos estágios de desenvolvimento, profundidade efetiva das raízes e fração crítica de depleção. Foram adotados os seguintes valores: Período de Safra: janeiro a março; Dados de precipitação: Estação Santarém (PA) (CLIMWAT, 2010); Dados Climáticos: Estação Santarém (PA) (CLIMWAT, 2010); Dados da cultura: Padrão FAO - arquivo Soja (FAO, 2010); e Dados do solo: Padrão FAO - arquivo solo médio (FAO, 2010). A escolha do arquivo de solo médio se deve à semelhança dos desse modelo da FAO com os solos predominantes na região de estudo, que são latossolo vermelho e latossolo amarelo, segundo a Secretaria Municipal de Agricultura e Abastecimento da cidade de Santarém-PA (PARÁ, 2016).

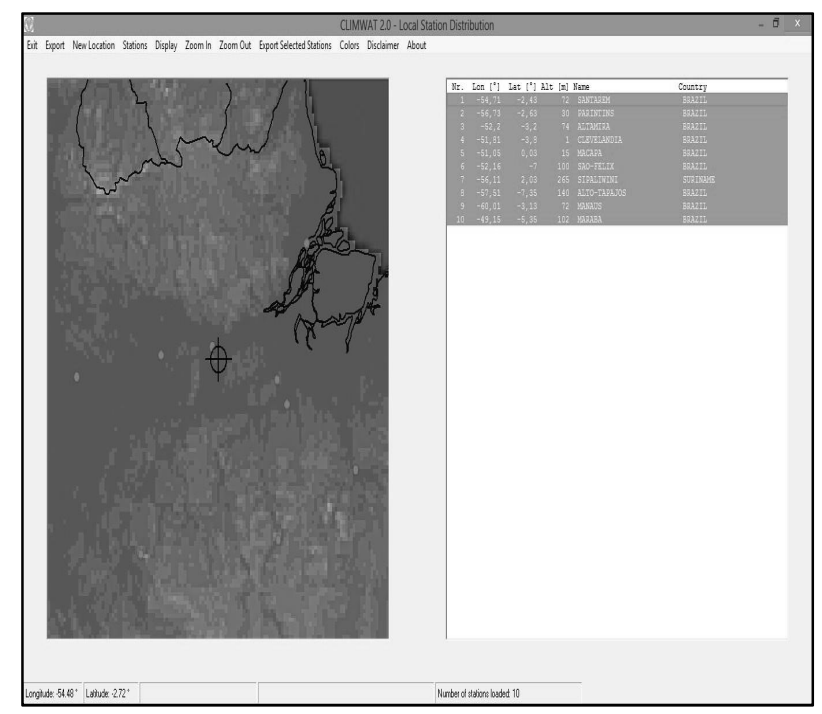

Figura 2: Tela do programa CLIMWAT mostrando estações de dados agrometeorológicos (círculos vermelhos) próximas à área de estudo (círculo maior com cruz no centro). Fonte: FAO, 2010.

Para cálculo de produtividade foi adotado o valor de 50 sacas.ha $^{-1}$ obtido durante as pesquisas de campo. Com base nesses dados, obteve-se uma evapotranspiração efetiva média diária da cultura de 2,57 mm.dia ${ }^{-1}$ e a evapotranspiração total para o período de cultura de $231,2 \mathrm{~mm}$ para os 90 dias de cultura, conforme apresenta o quadro 1.

Quadro 1: Dados obtidos do programa CROPWAT para a área de estudo.

\begin{tabular}{|c|c|c|c|c|c|c|c|c|}
\hline \multicolumn{7}{|c|}{ Área de estudo - Dados do CROPWAT (soja) } & & \\
\hline Mês & Estágio & $\begin{array}{c}\text { Coeficiente } \\
\text { Kc }\end{array}$ & $\begin{array}{l}\text { Evapotranspiração } \\
\text { da cultura mm.dia- } \\
1\end{array}$ & $\begin{array}{l}\text { Evapotranspiração } \\
\text { da cultura - mm. } \\
\text { dezena dias }\end{array}$ & $\begin{array}{c}\text { Chuva } \\
\text { Efetiva - } \\
\text { mm. dezena } \\
\text { dias } \\
\end{array}$ & $\begin{array}{l}\text { Demanda de } \\
\text { Irrigação }\end{array}$ & & \\
\hline Jan. & Inicial & 0,40 & 1,43 & 14,3 & 41,6 & 0.0 & & \\
\hline Jan. & Desenv. & 0,47 & 1,61 & 16,1 & 47,4 & 0.0 & JAN. & MED. \\
\hline Jan. & Médio & 0,89 & 3,00 & 33,0 & 48,7 & 0.0 & 63,4 & 2,04 \\
\hline Fev. & Médio & 1,08 & 3,53 & 35,3 & 49,9 & 0,0 & & \\
\hline Fev. & Médio & 1,08 & 3,44 & 34,4 & 51,8 & 0,0 & FEV. & MED. \\
\hline Fev. & Médio & 1,08 & 3,40 & 27,2 & 52,7 & 0,0 & 96,9 & 3,46 \\
\hline Mar. & Médio & 1,08 & 3,37 & 33,7 & 53,8 & 0,0 & & \\
\hline Mar. & Tardio & 0,88 & 2,73 & 27,3 & 55,0 & 0,0 & MAR. & MED. \\
\hline Mar. & Tardio & 0,54 & 1,65 & 9,9 & 29,8 & 0,0 & 70,9 & 2,28 \\
\hline & & & & 231,2 & 430,8 & 0,0 & & 2,57 \\
\hline
\end{tabular}


No quadro 1, a coluna 'Demanda de irrigação' com valores iguais a zero indica que não há necessidade de irrigação para a cultura na área de estudo durante o período. A coluna 'Chuva Efetiva' mostra que nesse período há uma precipitação média de 430,8mm, que excede o necessário para o cultivo. Com esses dados, a pegada verde resultou em $779,30 \mathrm{~m}^{3} \cdot \operatorname{ton}^{-1}$ para a área de estudo.

No caso da pegada azul, os dados obtidos indicaram que são necessários 75 L.ha $^{-1}$ de água para o preparo e diluição dos insumos, sendo esse processo repetido 5 vezes durante a safra. Considerando a produção da área, são necessários $0,125 \mathrm{~m}^{3} \cdot \operatorname{ton}^{-1}$ de água superficial ou subterrânea (PH azul) para a produção da soja na área de estudo. Para a pegada cinza da soja na área e período pesquisado, obteve-se o resultado de $166,67 \mathrm{~m}^{3}$.ton ${ }^{-1}$, utilizando-se a equação 2 e os dados constantes da tabela 2. Logo, a pegada hídrica total da soja na área pesquisada é $946,09 \mathrm{~m}^{3} \cdot$ ton $^{-1}$. A região apresentou um resultado $44 \%$ menor do que a média mundial para a cultura de soja e $49 \%$ menor que a média brasileira (MEKONNEN et al., 2010).

\section{DISCUSSÃO}

A estratégia de adaptação da pegada hídrica para diferentes contextos produtivos é utilizada em vários cenários, entre eles se pode citar Mekonnen et al. (2010) que gerou um padrão da pegada hídrica para grãos a nível mundial, além de demais estudos como o de Ercin et al. (2011) que resultou na pegada hídrica da soja em período de sequeiro (Se) e irrigada (I) na França e Arena et al. (2011) que mensurou a pegada hídrica da soja irrigada (CI) e não irrigada (SI) na Argentina.

Quadro 2: Dados de literaturas relevantes a nível mundial sobre a pegada hídrica da soja.

\begin{tabular}{|c|c|c|c|c|c|c|c|c|c|}
\hline \multicolumn{10}{|c|}{ Dados de literaturas relevantes sobre a PH da soja - Nível mundial } \\
\hline Literaturas & \multicolumn{2}{|c|}{$\mathrm{PH}$ verde } & \multicolumn{2}{|c|}{$\mathrm{PH}$ azul } & \multicolumn{2}{|c|}{$\mathrm{PH}$ cinza } & \multicolumn{2}{|c|}{$\mathrm{PH}$ total } & \multirow[b]{2}{*}{$\mathrm{m}^{3} \cdot$ ton $^{-1}$} \\
\hline $\begin{array}{l}\text { Mekonnen et al. } \\
\text { (2010) }\end{array}$ & \multicolumn{2}{|c|}{2037} & \multicolumn{2}{|c|}{70} & \multicolumn{2}{|c|}{37} & \multicolumn{2}{|c|}{2145} & \\
\hline \multirow{2}{*}{ Ercin et al. (2011) } & 1 & Se & 1 & Se & I & Se & 1 & $\mathrm{~S}$ & \\
\hline & 1255 & 2048 & 519 & 0 & 370 & 603 & 2145 & 2651 & \\
\hline \multirow{2}{*}{ Arena et al. (2011) } & $\mathrm{Cl}$ & $\mathrm{SI}$ & $\mathrm{Cl}$ & $\mathrm{SI}$ & $\mathrm{Cl}$ & $\mathrm{SI}$ & $\mathrm{Cl}$ & $\mathrm{SI}$ & \\
\hline & 1383.3 & 2084.6 & 875.5 & 0 & 313.4 & 356.1 & 2572,2 & 2440,7 & \\
\hline
\end{tabular}

Nota-se, por meio do quadro 2, que os dados obtidos através do presente trabalho (pegada hídrica total $=946,09 \mathrm{~m}^{3} \cdot$ ton $^{-1}$ ) têm valores bem abaixo das médias e estimativas mundiais de pegada hídrica da soja. Isto também pode ser observado quando são comparados os dados da área de estudo com dados e estimativas a nível nacional, conforme é exposto no quadro 3.

Quadro 3: Comparação de dados nacionais sobre a pegada hídrica da soja.

\begin{tabular}{|c|c|c|c|c|c|}
\hline \multicolumn{5}{|c|}{ Comparação de dados nacionais sobre a PH da soja } \\
\hline Literaturas & PH verde & PH azul & PH cinza & PH total & \\
\hline Mekonnen et al. (2010) & 2186 & 1 & 15 & $\mathbf{2 2 0 2}$ \\
\hline Kotsuka (2013) & 1792,7 & 0 & 416,67 & $\mathbf{2 2 0 9 , 3 7}$ \\
\hline $\begin{array}{c}\text { Dados desta pesquisa } \\
\text { (Santarém/Amazônia) }\end{array}$ & 779,30 & 0,125 & 166,67 & $\mathbf{9 4 6 , 0 9}$ & \\
\hline
\end{tabular}

Estão expressos no quadro 3 os dados obtidos da presente pesquisa e das duas literaturas nacionais mais condizentes com este trabalho. Sobre a pesquisa em si, por ser uma típica fazenda do estado do Pará, é considerável que seja base para representação da produção de soja no que tange ao bioma Amazônia. 
Referente à literatura, Kotsuka (2013) avaliou os conceitos de água virtual e da PH em si e utilizou a metodologia da pegada hídrica para obtenção de dados referentes à produção da soja de Maringá, Paraná no Bioma Mata Atlântica e do óleo de soja, enquanto Mekonnen et al. (2010) gerou médias da pegada hídrica para diversos grãos e nacionalidades, inclusive referentes à soja produzida no Brasil.

No mais, o quadro 3 apresenta dados obtidos no mesmo país e na mesma cultura, porém com valores bem divergentes. Isto pode decorrer da característica da região amazônica quanto ao regime de chuvas constantes, pois, como nessa região há um intenso volume de precipitação em determinada época, a grande maioria das fazendas produtoras e das atividades nelas desenvolvidas faz ser infrequente a necessidade de captar recurso hídrico subterrâneo ou superficial. Essa situação acarreta em menores valores no que se refere à pegada hídrica azul. Isto é, há balanço hídrico positivo, já que a precipitação média na Amazônia no período da safra é de $430,8 \mathrm{~mm}$ que, segundo o quadro 2, ultrapassa o necessário para o cultivo da soja nessa região.

Deste modo, fortalecendo a análise através dos dados do quadro 3, pode-se afirmar que nas demais regiões brasileiras há uma maior utilização de irrigação, pois, nesses locais não há precipitação que propicie o cultivo sem ser necessária irrigação através da captação de água superficial ou subterrânea (PH azul). Por conseguinte, nota-se que, do ponto de vista hídrico, é mais viável a produção de soja na Amazônia do que em outro local do país.

Considerando que o resultado da PH estar mais elevado pode significar abundância de recurso hídrico ou necessidade de gestão melhorada, é sempre interessante frisar a necessidade de se utilizar a água com eficiência, seja ela para irrigação ou outro fim. Portanto, os dados adquiridos com essa pesquisa podem variar negativa ou positivamente no transcorrer dos anos, dependendo da implantação de medidas como a utilização eficiente da água - gestão, disponibilidade hídrica - que está cada vez menor - entre outras, afinal a demanda de água para irrigação só aumenta, contrastando com a disponibilidade desse recurso.

\section{CONCLUSÃO}

Como indicador de sustentabilidade, a pegada hídrica é capaz de monitorar o impacto humano sobre o meio ambiente. Tal indicador deve ser usado e interpretado em conjunto visando a avaliação dos impactos ambientais de produção e consumo. Neste trabalho, foram abordados aspectos da irrigação, e considerando seus efeitos sobre a modificação do meio ambiente, tais como: salinização do solo, contaminação dos recursos hídricos, disponibilidade de água para outras atividades (uso múltiplo da água), consumo de energia e saúde da população (BERNARDO, 1997), subentende-se que seu uso eficiente é imprescindível para a prevenção de impactos ambientais.

Através desta pesquisa ficou evidente que, no que tange ao aspecto hídrico, a Amazônia é mais viável para a cultura de soja que as demais regiões brasileiras. Isto ficou exposto devido ao grande volume de precipitação que há na região amazônica que faz não ser necessário usar de irrigação em culturas como a da soja nesta região. No mais, sabe-se que o resultado da PH estar mais elevado pode significar abundância de recurso hídrico ou necessidade de aprimorar a gestão e isso leva à compreensão de que as produções do 
restante do país necessitam fazer um melhor manejo da agricultura irrigada e da drenagem agrícola, além de precisarem aperfeiçoar a eficiência dos métodos/sistemas de irrigação como meio de prevenção de possíveis impactos.

Questionamentos podem surgir com relação à proporcionalidade entre a produção de soja e o uso de água neste plantio. Em decorrência disso, foi elaborada a tabela 3, cujas informações são do IBGE (2013, 2016) e da APROSOJA (2016) e trazem os estados e seus respectivos municípios que mais produzem nacionalmente. Deste modo, nota-se através da tabela 3, que apesar da pegada hídrica total obtida na pesquisa ser menor isso não interfere nos resultados da produção, pois a produtividade da soja obtida na área de pesquisa (50 sacas.ha-1) está na média dos estados e municípios que mais produzem do país e, em alguns casos, até maior.

Tabela 3: Ranking da produção de soja no Brasil: Ano 2016.

\begin{tabular}{|c|c|c|}
\hline $\begin{array}{c}\text { Ranking de produção de soja por estado (IBGE } \\
\text { 2016) }\end{array}$ & $\begin{array}{c}\text { Produção de soja por municípios (IBGE } \\
\text { 2013) }\end{array}$ & $\begin{array}{c}\text { Produção (APROSOJA 2016) } \\
\text { sacas.ha-1 }^{-1}\end{array}$ \\
\hline 10 Mato Grosso & Sorriso & 47,46 \\
\hline 2o Paraná & Toledo & 51,5 \\
\hline 3o Rio Grande Do Sul & Tudanciretã & 49,5 \\
\hline 4o Goiás & Jataí & 52 \\
\hline 5o Mato Grosso Do Sul & Maracaju & 53,66 \\
\hline 6o Minas Gerais & Unaí & 35 \\
\hline 7o Bahia & Formosa do Rio Preto & 55,16 \\
\hline 8o São Paulo & Itapeva & 55,66 \\
\hline 9o Santa Catarina & Campos Novos & 32,16 \\
\hline 10 Tocantins & Campos Lindos & \\
\hline
\end{tabular}

Portanto, espera-se que esta pesquisa sirva como insumo para ações de gestão melhorada de recursos hídricos em produções de soja e demais culturas que fazem uso de irrigação. Almejando assim, que medidas sejam tomadas em prol da prevenção de impactos no meio ambiente e de uma agricultura mais eficiente com cada vez maior produtividade e menor desperdício de água.

\section{REFERÊNCIAS}

ALDAYA, M. M.; HOEKSTRA, A. Y.. The water needed for Italians to eat pasta and pizza. Agricultural Systems, v.103, p.351-360, 2010.

APROSOJA. Associação dos Produtores de Soja do Brasil. Estatística da soja: levantamento da safra. Cuiabá: APROSOJA, 2016.

ARENA, A. P.; PIASTRELLINI, R.; CIVIT, B.. Water Footprint of soybean production in Argentina. Berlim: 2011.

BERNARDO, S.. Impacto ambiental da irrigação no Brasil. In: SILVA, D. D.; PRUSKI, F. F.. Recursos hídricos e desenvolvimento sustentável da agricultura. Brasília: MMA, 1997. p.79-88.

CARMO, R. L.; OJIMA, A. L. R. O.; OJIMA, R.; NASCIMENTO, T. T.. Água virtual, escassez e gestão: o Brasil como grande 'exportador' de água. Ambiente e Sociedade, Campinas, v.10, n.2, p.83-96, 2007.
CHAPAGAIN, A. K.; HOEKSTRA, A. Y.. Virtual water flows between nations in relation to trade in livestock and livestock products. Amsterdã: IHE, 2003.

CHAPAGAIN, A. K.; HOEKSTRA, A. Y.. Water footprints of nations. Value of Water Research Report Series, Delft, v.2, n.16, 2003.

CHRISTOFIDIS, D.. Água, irrigação e agropecuária sustentável. Revista de Política Agrícola, Brasília, v.22, n.1, 2013.

EMBRAPA. Empresa Brasileira de Pesquisa Agropecuária. Recomendações técnicas para a cultura da soja na região central do Brasil. Londrina: Embrapa, 2000

ERCIN, A. E.; ALDAYA, M. M.; HOEKSTRA, A. Y.. Corporate water footprint accounting and impact assessment: the case of the water footprint of sugar-containing carbonated beverage. Water Resources Management, v.25, p.721-741, 2011. 
FAO. Food and Agriculture Organization of the United Nations. CROPWAT 8.0 model. Roma: FAO, 2010.

GERBENS-LEENES, W.; HOEKSTRA, A. Y.. The water footprint of sweeteners and bioethanol. Environment International, v.40, p.202-211, 2012.

HOEKSTRA, A. Y.. How sustainable is Europe's water footprint?. Water and Wastewater International, v.26, n.2, p.24-26, 2011.

HOEKSTRA, A. Y.; CHAPAGAIN, A. K.. The water footprints of morocco and the Netherlands: global water use as a result of domestic consumption of agricultural commodities. Ecological Economics, v.64, p.143-151, 2007.

HOEKSTRA, A. Y.; CHAPAGAIN, A. K.; ALADAYA, M. M.; MEKONNEN, M. M.. Manual de Avaliação da Pegada Hídrica: estabelecendo o Padrão Global. São Paulo: USP, 2011.

HOEKSTRA, A. Y.; Human appropriation of natural capital: A comparison of ecological footprint and water footprint analysis. Ecological Economics, v.68, 2009.

IBGE. Instituto Brasileiro de Geografia e Estatística. Economia Agropecuária: estatísticas da previsão de safras. Rio de Janeiro: IBGE, 2013.

IBGE. Instituto Brasileiro de Geografia e Estatística. Estatística: indicadores da agropecuária. Rio de Janeiro: IBGE, 2016.

KOTSUKA, L. K.. Avaliação dos conceitos de água virtual e pegada hídrica na gestão de recursos hídricos: estudo de caso da soja e óleo de soja. Dissertação (Mestrado em engenharia de Recursos Hídricos e Ambiental) Universidade Federal do Paraná, Curitiba, 2013.

MALAVOLTA, E.. ABC da adubação. 5 ed. São Paulo: Ceres, 1989.
MEKONNEN, M. M.; HOEKSTRA, A. Y.. The green, blue and grey water footprint of farm animals and animal products. Amsterdã: Water FootPrint, 2010.

MENDONÇA, C. B.; TADEU, N. D.; SINISGALLI, P. A. A.. Pegada hídrica da bovinocultura de corte no Brasil: uma comparação entre a produção em pastagem manejada e não manejada. In: SIMPÓSIO BRASILEIRO DE RECURSOS HÍDRICOS. Anais. Bento Gonçalves: ABRH, 2013.

PALHARES, J. C. P.. Pegada hídrica de suínos e o impacto de estratégias nutricionais. Revista Brasileira de Engenharia Agrícola e Ambiental, Campina Grande, v.18, n.5, p.533-538, 2014.

PALHARES, J. C. P.. Pegada hídrica dos suínos abatidos nos Estados da Região Centro-Sul do Brasil. Acta Scientiarum, Maringá, v.33, n.3, p.309-314, 2011.

PARÁ. Prefeitura de Santarém. Plano Municipal de Agropecuária: solo. Santarém: 2016.

PIMENTEL, D.. Water Resources: Agricultural and Environmental Issues. Bioscience, v.54, n.10, p.909-918, 2004.

RODRIGUES JUNIOR, U. J.; DZIEDZIC, M.; PINHEIRO, A. Pegada hídrica: consumo e impactos gerados na cadeia produtiva da soja na Amazônia. In: CONGRESSO BRASILEIRO DE GESTÃO AMBIENTAL. Anais. Porto Alegre: IBEAS, 2015.

SILVA, V. P. R.; ALEIXO, D. O.; DANTAS NETO, J.; MARACAJÁ, K. F. B.; ARAÚJO, L. E.. Uma medida de sustentabilidade ambiental: pegada hídrica. Revista Brasileira de Engenharia Agrícola e Ambiental, Campina Grande, v.17, n.1, p.100-105, 2013.

YU, Y.; HUBACEK, K.; FENG, K.; GUAN, D.. Assessing regional and global water footprints for the UK. Ecological Economics, v.69, p.1140-1147, 2010.

A CBPC - Companhia Brasileira de Produção Científica (CNPJ: 11.221.422/0001-03) detém os direitos materiais desta publicação. Os direitos referem-se à publicação do trabalho em qualquer parte do mundo, incluindo os direitos às renovações, expansões e disseminações da contribuição, bem como outros direitos subsidiários. Todos os trabalhos publicados eletronicamente poderão posteriormente ser publicados em coletâneas impressas sob coordenação da Sustenere Publishing, da Companhia Brasileira de Produção Científica e seus parceiros autorizados. Os (as) autores (as) preservam os direitos autorais, mas não têm permissão para a publicação da contribuição em outro meio, impresso ou digital, em português ou em tradução. 